\title{
Antenatal Dexamethasone Administration Impairs Normal Postnatal Lung Growth in Rats
}

\author{
SATORU OKAJIMA, TADASHI MATSUDA, KAZUTOSHI CHO, YOSHINORI MATSUMOTO, \\ YOSHIYASU KOBAYASHI, AND SEIICHIRO FUJIMOTO \\ Department of Pediatrics [S.O., T.M.], Division of Delivery [S.O., T.M., K.C., S.F.], and Department of \\ Obstetrics and Gynecology [S.F.], Hokkaido University Hospital, Hokkaido University School of Medicine, \\ Sapporo 060-8638, Hokkaido, Japan; Department of Pediatrics, Hokkaido Social Work Association \\ Obihiro Hospital, Obihiro 080-0805, Hokkaido, Japan [Y.M.]; and Department of Veterinary Pathology, \\ Obihiro University of Agriculture and Veterinary Medicine, Obihiro 080-8055, Hokkaido, Japan [Y.K.]
}

\begin{abstract}
ABST
Our purpose was to determine the influences of antenatal
dexamethasone administration on neonatal lung development in
rats. Dexamethasone $(0.4 \mathrm{mg} / \mathrm{kg}$ maternal body weight per day)
was administered i.p. on the $21 \mathrm{st}$ d (group 1) or on the 20th and
21st d (group 2) of gestation in Sprague Dawley rats with timed
pregnancies. After natural deliveries, the lungs of the pups $1-60$
d of age were removed and processed for morphometric analysis.
In 60-d-old pups, groups 1 and 2 both showed a lower numerical
density of alveoli and a larger mean alveolar radius than control
\end{abstract}
pups. Antenatal administration of dexamethasone to rats impairs the normal postnatal lung growth. Some aspects of the use of antenatal glucocorticoid therapy in humans may require reconsideration. (Pediatr Res 49: 777-781, 2001)

DXM, dexamethasone
CLD, chronic lung disease
Antenatal glucocorticoid therapy, including the administration of DXM and betamethasone, is widely used in the perinatal care of premature infants (1-3) The effects of antenatal glucocorticoid therapy include a reduction in the severity of respiratory distress syndrome, reductions in the incidences of several other complications associated with prematurity (hypotension, intracranial hemorrhage, etc.), and a reduction in mortality. In animal experiments, glucocorticoid administration appears to accelerate not only the establishment of the surfactant system, but also the activities of antioxidant enzymes (4) and, via surfactant-independent mechanisms, an increase in alveolar wall compliance (5).

The growth of the lung during the human perinatal period consists of several phases (6): 1) the establishment of a surfactant system, 2) an increase in the number of alveoli through division of the existing alveoli (alveolarization), and 3) alveolar wall thinning and capillary fusion (microvascular maturation). The latter two phases are accompanied by structural changes. Alveolarization occurs mainly between the 35th wk of gestation and approximately the third postnatal year. Microvascular maturation begins after birth and is completed by $5 \mathrm{y}$

Received August 28, 2000; accepted January 3, 2001

Correspondence and reprint requests: Satoru Okajima, M.D., Department of Obstetrics and Gynecology, Hokkaido University School of Medicine, North 15, West 7, Kita-ku, Sapporo 060-8638, Hokkaido, Japan; e-mail: okaji@tara.med.hokudai.ac.jp of age. Alveolarization is said to occur only in the presence of immature thick septa (6).

These three phases of lung growth have been observed in most mammals (6), but the times at which the phases occur differ among species. For example, the pulmonary ultrastructure of newborn rats corresponds to that of humans at about the 28th wk of gestation. In other words, rats are born before the process of alveolarization has begun. Alveolarization in the rat lung takes place predominantly within the first 2 wk of life, with microvascular maturation occurring during the third wk (7).

Postnatal administration of DXM $(1 \mu \mathrm{g} / \mathrm{d}$, i.e. $3.3-12.5$ $\mu \mathrm{g} \cdot \mathrm{kg}^{-1} \cdot \mathrm{d}^{-1}$, from $\mathrm{d} 2$ to 15$)$ is known to impair subsequent alveolarization in rats $(8,9)$ During the first 2 wk, DXM accelerates microvascular maturation and suppresses alveolarization. One week after drug withdrawal, the trend toward precocious maturation is reversed. The alveolar wall returns to a more immature state, and a delayed burst of alveolarization begins. At $d$ 60, the lungs appear emphysematous, with larger and fewer alveoli, suggesting that the delayed alveolarization is insufficient to compensate for the initial deficit.

We hypothesized that antenatal DXM administration might also result in these phenomena in newborn rats. To test this hypothesis, we investigated antenatal DXM-induced structural changes in neonatal rat lungs using light-microscopic morphometry. 


\section{METHODS}

This study was approved by the Animal Care and Use Committee of Hokkaido University School of Medicine.

Animals. Newborn rats $(n=108)$ from Sprague Dawley rats ( $n=21$ ) with timed pregnancies, weighing $270-330 \mathrm{~g}$ on the 20th $d$ of pregnancy (term, $22.5 \mathrm{~d}$ ), were used for the experiments.

Drug administration. Decadron $(1 \mathrm{~mL}$ contains $4 \mathrm{mg}$ of dexamethasone phosphate) solution was diluted with isotonic saline (1:9, Decadron to saline), and a final DXM dose of 0.4 $\mathrm{mg}(1 \mathrm{~mL})$ per kilogram of body weight was administered to the mothers. The pregnant rats were divided into three groups of seven animals each. Rats from group 1 were given $1 \mathrm{~mL} / \mathrm{kg}$ body weight of isotonic saline on the 20th $\mathrm{d}$ of gestation and a single dose of DXM on the 21st d by i.p. injection. Rats from group 2 received two doses of DXM, both on the 20th and the $21 \mathrm{st} \mathrm{d}$, and rats from the control group received isotonic saline injections on the both days. All injections were given between 0800 and $0900 \mathrm{~h}$. All rats delivered their pups naturally within $48 \mathrm{~h}$ of the last injection. The total number of pups was 213 . Thirty-six pups from each group (a total of 108 pups) were randomly selected, irrespective of sex, on $\mathrm{d} 1$ for use in this study. Normalization of litter sizes was not performed for practical reasons.

Lung fixation and tissue processing. On d 1, 4, 7, 10, 13, $21,35,44$, and 60 after birth, four newborn rats from each group were anesthetized with an intraperitoneal injection of Nembutal (Abbott Laboratories, Abbott Park, IL, U.S.A.; $1 \mathrm{~mL}$ Nembutal contains $50 \mathrm{mg}$ of pentobarbital) at a dose of 0.3 $\mathrm{mL} / 100 \mathrm{~g}$ body weight. The lungs were fixed by intratracheal instillation of $10 \%$ buffered formalin at a pressure of $20 \mathrm{~cm}$ $\mathrm{H}_{2} \mathrm{O}$ for $10 \mathrm{~min}$. After ligation of the trachea and removal of the chest organs, fixation was continued by placing the lungs in buffered formalin for $>48 \mathrm{~h}$. Before and after the last fixation, the volume of the whole lung was measured by water displacement (10) to assess fixation failure $(>5 \%$ loss of former volume.)

For practical reasons, only the left lung was processed for light-microscopic morphometric evaluation. A single lobe of the rat lung has been shown to be a representative sampling of the morphometry of the entire organ (11). To obtain vertical sections $(12,13)$, the tissue was processed as follows: the vertical axis of each left lung was determined, and the lung was dissected into a few planes along that axis. Each plane was $<4$ $\mathrm{mm}$ thick and did not exceed the depth of the cassette cases used for embedding. The blocks were arranged in the cassette cases so that the vertical axes were parallel to each other, and the planes were embedded. The specimens were then cut into $2-\mu \mathrm{m}$-thick sections and stained with hematoxylin and eosin.

Light-microscopic morphometry. The sections were analyzed at a magnification of $\times 400$ using MCID (Microcomputer Imaging Device, Imaging Research Inc., St Catharines, Ontario, Canada). TIFF images ( $1280 \times 1024$ pixels, $45.16 \times 36.12$ $\mathrm{cm}$.) were captured and stored using this software. Ten images from each left lung were randomly selected for morphometric procedures (total number of images, 1080). The images were transferred to a PICT format and examined using Stereology
Toolbox (Morphometrix, Davis, CA, U.S.A.). This software contains six standard grids for morphometry. The images were examined using a horizontal cycloid grid (Fig. 1a), and the following two variables were estimated: Vav, the volume density of alveolar spaces (air spaces excluding bronchi and bronchioli in a unit of lung volume); and $S v$, the surface density of alveolar walls (total surface areas in a unit of lung volume).

The PICT images were superimposed on the grid according to their vertical axes, and the regions of alveolar spaces ( $\mathrm{Vav}$ ) and intersections between alveolar walls and cycloids $(S v)$ were counted. Five fields per image (the center and the four corners) were superimposed and counted. Thus, 50 fields were analyzed for each left lung. The total number of points and intersections in each left lung was $>400$ (12).

Calculated variables. Using the two variables defined above, the following two variables were calculated to further clarify the morphologic characteristics of the lung: $n v$, numerical density of alveoli (number of alveoli in a unit of lung volume); and $r$, average alveolar radius. These variables were calculated as follows:

$$
\begin{gathered}
V a v=n v \times 4 \pi r^{3} / 3 \\
S v=n v \times 4 \pi r^{2} \\
r=3 \operatorname{Vav} / S v \\
n v=S v / 4 \pi r^{2}
\end{gathered}
$$
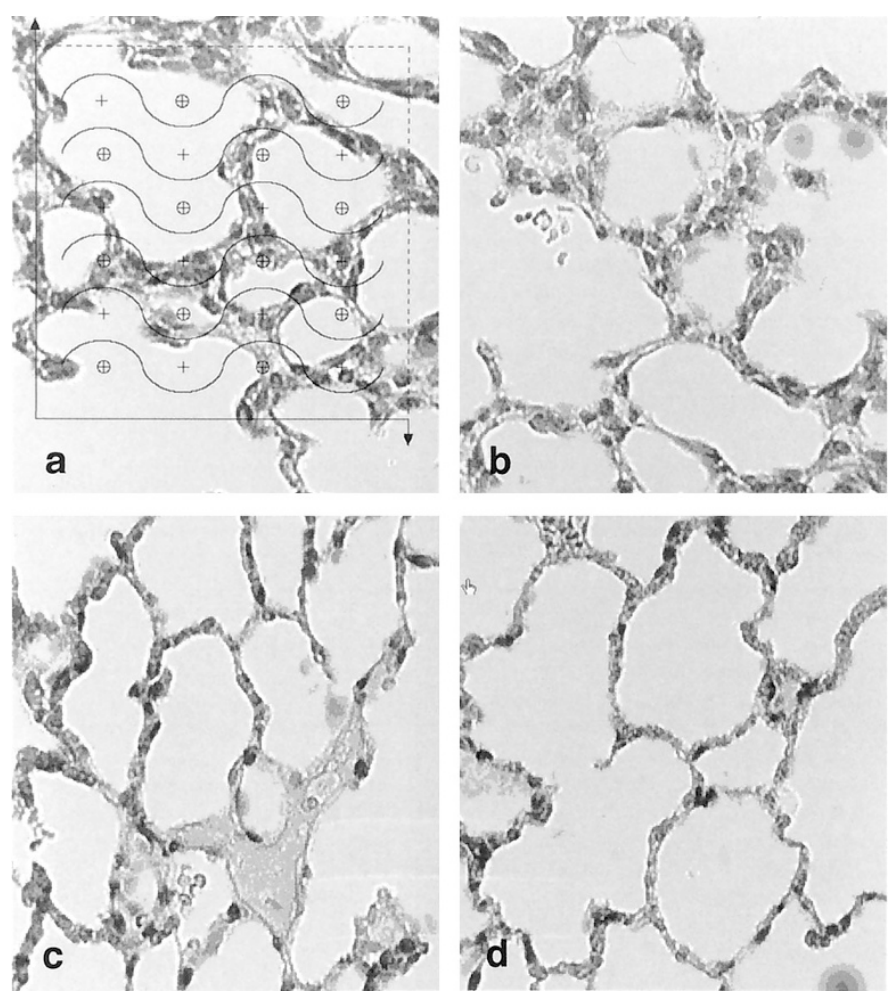

Figure 1. Representative photomicrographs of lung sections. $a$, control/d 10; note that a horizontal cycloid grid is superimposed. $b$, group $1 / \mathrm{d} 10 . c$, control/d 60. $d$, group 1/d 60. Magnification, $\times 400$. 
Statistical analyses. The three groups were statistically compared using Scheffe's test, which is compatible to compare three or more groups at several points. A $p<0.05$ was considered to be statistically significant.

\section{RESULTS}

One rat from group 1/d 1 was excluded from the study because the fixation procedure failed. Thus, group 1/d 1 contained three rats, whereas all other groups contained four.

Representative photomicrographs of control and group 1 (d 10 and 60) lung sections are shown in Figure 1.

Body weight. There were no significant differences in body weight among the three groups on any experimental days (Fig. 2).

Surface density of alveolar walls. On d 10 and 60, both group 1 and group 2 exhibited a significantly lower $S v$ than the control group $\left(\mathrm{d} 10,269.1 \pm 12.0 \mathrm{~cm}^{-1}\right.$ and $273.1 \pm 10.5$ $\mathrm{cm}^{-1}$ versus $295.8 \pm 5.4 \mathrm{~cm}^{-1}$, respectively; $\mathrm{d} 60,375.3 \pm$ $15.3 \mathrm{~cm}^{-1}$ and $367.3 \pm 37.1 \mathrm{~cm}^{-1}$ versus $501.2 \pm 9.6 \mathrm{~cm}^{-1}$, respectively; all values shown as the mean $\pm \mathrm{SD}$; Fig. 3). No significant differences were detected on other days.

Numerical density of alveoli. On d 10, group 1 exhibited a lower $n v$ than the control group $\left(408.9 \pm 51.9 / \mathrm{mm}^{3}\right.$ versus $603.6 \pm 34.5 / \mathrm{mm}^{3}$, respectively). On d 44 and 60 , both group 1 and group 2 exhibited a lower $n v$ than the control group (d $44,792.8 \pm 278.0 / \mathrm{mm}^{3}$ and $763.4 \pm 201.6 / \mathrm{mm}^{3}$ versus 1265.1 $\pm 121.3 / \mathrm{mm}^{3}$, respectively; d $60,978.9 \pm 182.9 / \mathrm{mm}^{3}$ and $1037.6 \pm 291.6 / \mathrm{mm}^{3}$ versus $1942.3 \pm 130.6 / \mathrm{mm}^{3}$, respectively; Fig. 4).

Average alveolar radius. On d 10, group 1 exhibited a larger $r$ than the control group $(72.6 \pm 3.6 \mu \mathrm{m}$ versus $62.5 \pm 1.3 \mu \mathrm{m}$, respectively). On d 60, both group 1 and group 2 exhibited a larger $r$ than the control group $(55.7 \pm 4.1 \mu \mathrm{m}$ and $54.0 \pm 5.5$ $\mu \mathrm{m}$ versus $45.4 \pm 1.1 \mu \mathrm{m}$, respectively; Fig. 5).

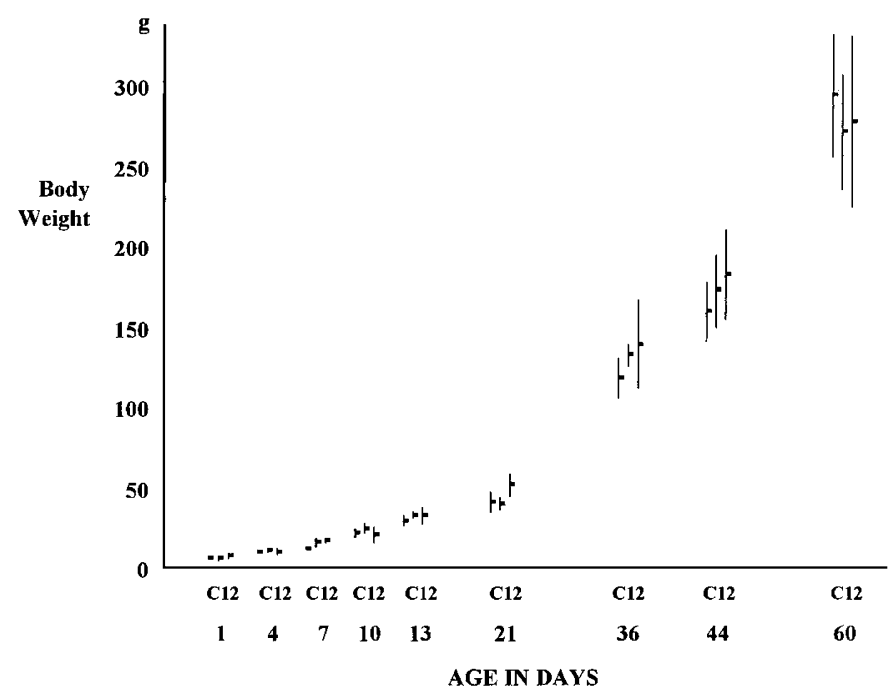

Figure 2. Changes in body weight $(\mathrm{g})$ as a function of postnatal age for the controls $(C)$, group $1(1)$, and group 2 (2); bars indicate the mean $\pm \mathrm{SD}$.

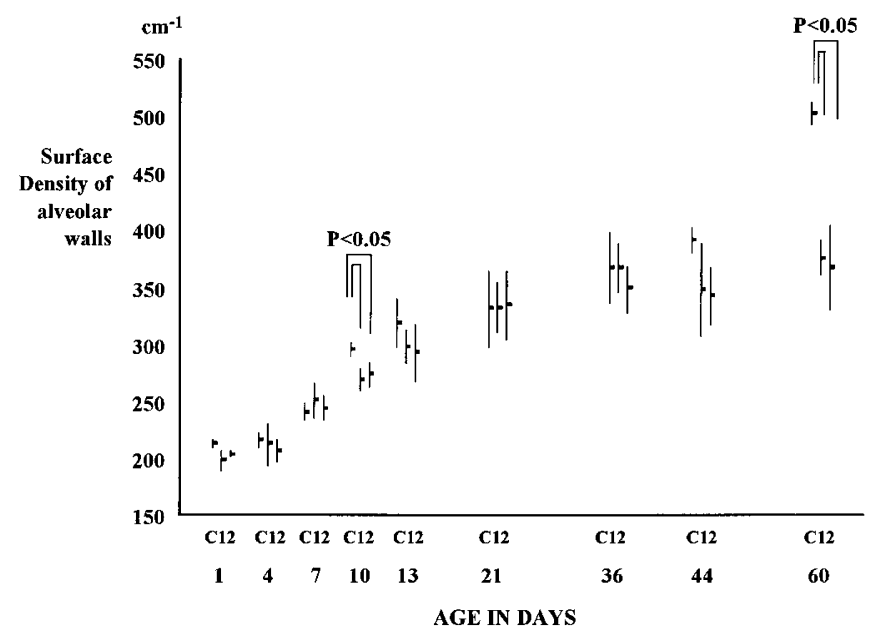

Figure 3. Changes in surface density of alveolar walls $\left(S v, \mathrm{~cm}^{-1}\right)$ as a function of postnatal age for the controls $(C)$, group 1 (1), and group 2 (2); bars indicate the mean $\pm \mathrm{SD}$. Note that the $S v$ values of groups 1 and 2 were significantly lower than those of the control group on d 10 and 60 .

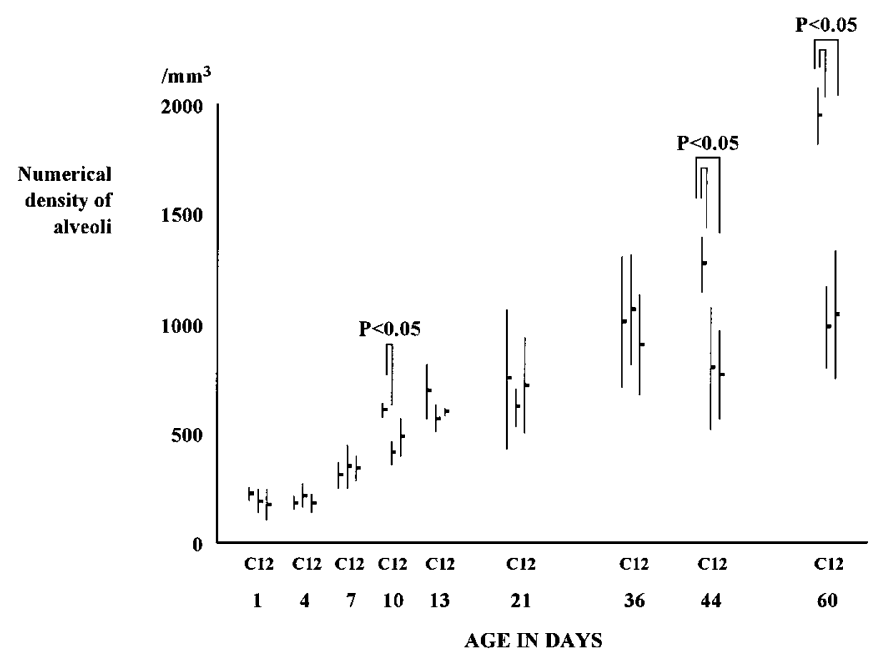

Figure 4. Changes in numerical density of alveoli $\left(n v\right.$, per $\left.\mathrm{mm}^{3}\right)$ as a function of postnatal age for the controls $(C)$, group 1 (1), and group 2 (2); bars indicate the mean $\pm \mathrm{SD}$. Note that the $n v$ of group 1 was lower than that of the control group on d 10, and that the $n v$ values of groups 1 and 2 were lower than those of the control group on $\mathrm{d} 44$ and 60 .

\section{DISCUSSION}

The influence of postnatal DXM administration on postnatal alveolarization in the rat has been studied in detail by Massaro et al. (8) and Tschanz et al. (9). The latter author stated that postnatal DXM treatments suppress alveolarization by promoting precocious microvascular maturation, with the result that on $\mathrm{d} 60$, the lungs appear emphysematous, with larger and fewer alveoli compared with controls. Inasmuch as rats are fully grown and microvascular maturation has been completed by $\mathrm{d} 60$, this emphysematous change in treated rats is thought to be irreversible. Massaro et al. (8) reported similar findings with antenatally administered DXM. Subsequently, however, they examined the effect of antenatal DXM administration on the lung's gas exchange surface area and the number of alveoli only up to d 14 (14). Our data showed antenatal administration of DXM to result in phenomena very similar to those observed 


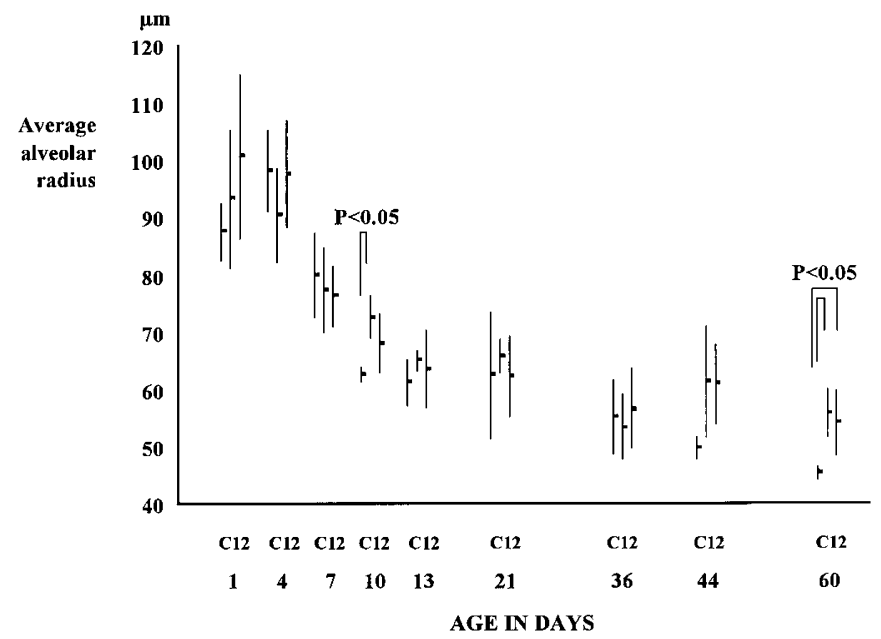

Figure 5. Changes in average alveolar radius $(r, \mu \mathrm{m})$ as a function of postnatal age for the controls $(C)$, group 1 (1), and group 2 (2); bars indicate the mean $\pm \mathrm{SD}$. Note that the $r$ of group 1 was higher than that of the control group on $\mathrm{d} 10$, and that the $r$ values of groups 1 and 2 were higher than those of the control group on $\mathrm{d} 60$.

after the postnatal administration of DXM as reported by Tschanz et al. (9). As shown in Figures 3 and 4, the first burst of alveolarization at approximately d 10 seen in the control group was significantly suppressed in the DXM-treated groups. Then, catch-up of alveolarization apparently took place in the DXM-treated groups and reached the normal level between $\mathrm{d}$ 13 and 36. These changes of alveolarization in the DXMtreated groups, namely suppression at first and subsequent catch-up, were consistent with those of the postnatal DXM administration reported by Tschanz et al. (9), in which they described that suppression of alveolarization by DXM recovered at approximately $1 \mathrm{wk}$ after the withdrawal, and then a decline toward immaturity of alveolar walls and a delayed burst of alveolarization took place. In this context, our observation would reflect a true phenomenon. After d 36, a time when the alveolarization proceeded further in the control group, the levels reached in the DXM-treated groups were maintained, leading to significantly lower $S v$ and $n v$ of alveoli. Changes in alveolar radius during the course coincided with those of $S v$ and $n v$ (Fig. 5): significantly larger radii were seen in DXM-treated groups around d 10 and also d 60, compared with the controls. Thus, DXM-treated groups ultimately had fewer and larger alveoli than the untreated group. We conclude that the mechanisms underlying our results are also precocious microvascular maturation, delayed alveolarization, and failure to compensate for these effects, as proposed by Tschanz et al. (9) in postnatal DXM administration. It means that antenatal DXM inhibited not only alveolarization for the first $10 \mathrm{~d}$, but also potentials of alveolarization by $60 \mathrm{~d}$ in rats.

Our choice for the dose of DXM $(0.4 \mathrm{mg} / \mathrm{kg})$ was determined referring to that of clinical use $(8 \mathrm{mg} \times 3$ or $12 \mathrm{mg} \times$ 2 ). We were convinced that the dose was enough to exhibit affects on lungs of newborn rats similar to postnatal administration, because the dose of postnatal DXM was so much lower than that of clinical use for CLD (15-17), i.e. 3.3-12.5 $\mu \mathrm{g} \cdot \mathrm{kg}^{-1} \cdot \mathrm{d}^{-1}$ versus $0.5 \mathrm{mg} \cdot \mathrm{kg}^{-1} \cdot \mathrm{d}^{-1}(18,19)$. As antenatal DEX crosses the placenta to the fetus and is cleared rapidly,
(20) the morphologic changes that we have observed must occur as a result of shorter period of effect than postnatal administration. It is true that the extrapolation to humans from our rat model with rapid growth, and therefore possibly a relatively prolonged exposure to DXM, is problematic. Although human studies have shown no evidence of impaired lung function in children exposed to antenatal glucocorticoids in general $(21,22)$, we think that our results suggest two specific points of concern regarding glucocorticoid therapy during the perinatal period. First, the effects of repetitive administrations of antenatal glucocorticoids on human lung growth remain uncertain. In clinical practice, repetitive courses of antenatal glucocorticoids are administered at 7-d intervals and are frequently used if preterm delivery does not occur (23). A number of observations have recently been published that demonstrate the risk of this repetitive administration of antenatal glucocorticoids (24-26). For this reason, two DXM administration regimens were used in the present experiment. Although our data showed no significant differences between groups 1 and 2, these data do not rule out the possibility of a dose-dependent influence on the human lung. We suspect that the repetitive administration of antenatal glucocorticoids, i.e. relatively prolonged exposure to glucocorticoids, should be reconsidered from the perspective of postnatal lung growth. Second, the effects of glucocorticoids in combination with other risk factors for severe CLD (15-17) must be examined. One of the characteristic changes seen in CLD is the development of fewer and larger alveoli. The cause of this morphologic change is unknown and must be multifactorial, but the involvement of glucocorticoids is feasible, because they are commonly used for antenatal and postnatal treatments $(18,19)$. Furthermore, pathologic changes in the lung in CLD patients are quite similar to those of our DXM-treated rats. There is solid evidence that antenatal glucocorticoids are not associated with an increased incidence of CLD (27), but the possibility that antenatal glucocorticoid administration might worsen morphologic changes in CLD cannot be ruled out.

It is apparent that there has been considerable improvement in perinatal care, which might allow for decreased use or for lower doses of glucocorticoids. In conclusion, we propose that antenatal glucocorticoid therapy should be reconsidered, not necessarily in general, but rather, for example, in terms of dosage or indications, because of its possible relation to exacerbation of CLD.

\section{REFERENCES}

1. Liggins GC 1969 Premature delivery of fetal lambs infused with glucocorticoids. J Endocrinol 45:515-523

2. Collaborative Group on Antenatal Steroid Therapy 1981 Effect of antenatal dexamethasone administration on the prevention of respiratory distress syndrome. Am J Obstet Gynecol 141:276-287

3. National Institutes of Health 1994 Effect of corticosteroids for fetal maturation on perinatal outcomes. Bethesda, MD, NIH Consensus Statement 12:1-24

4. Frank L, Lewis PL, Sosenko IRS 1985 Dexamethasone stimulation of fetal rat lung antioxidant enzyme activity in parallel with surfactant stimulation. Pediatrics 75:569574

5. Fiascone JM, Jacobs HC, Moya FR, Mercurio MR, Lima DM 1987 Betamethasone increases pulmonary compliance in part by surfactant-independent mechanisms in preterm rabbits. Pediatr Res 22:730-735

6. Thurlbeck WM 1995 Lung growth and development. In: Thurlbeck WM, Churg AM (eds) Pathology of the Lung, 2nd Ed. Thieme Medical Publishers, New York, pp $37-87$ 
7. Burri PH 1974 The postnatal growth of the rat lung: III. Morphology Anat Rec 180:77-98

8. Massaro D, Teich N, Maxwell S, Massaro GD, Whitney P 1985 Postnatal development of alveoli: regulation and evidence for a critical period in rats. J Clin Invest 76:1297-1305

9. Tschanz SA, Damke BM, Burri PH 1995 Influence of postnatally administered glucocorticoids on rat lung growth. Biol Neonate 68:229-245

10. Scherle W 1970 A simple method for volumetry of organs in quantitative stereology. Mikroskopie 26:57-60

11. Zelter TB, Bertacchini M, Messerli A, Burri PH 1990 Morphometric estimation of regional differences in the rat lung. Exp Lung Res 16:145-158

12. Bolender RP, Hyde DM, Dehoff RT 1993 Lung morphometry: a new generation of tools and experiments for organ, tissue, cell, and molecular biology. Am.J.Physio 265:L521-L548.

13. Weibel ER 1979 Practical methods for biological morphometry. In: Weibel ER (ed) Stereological Methods,. Vol 1. Academic, London

14. Massaro GD, Massaro D 1992 Formation of alveoli in rats: postnatal effect of prenata dexamethasone. Am J.Physiol 263:L37-L41

15. Northway WH, Rosan RC, Porter D 1967 Pulmonary disease following respiratory therapy of hyaline membrane disease: bronchopulmonary dysplasia. N Engl J Med 276:357-368

16. Wilson MG, Mikity VG 1960 A new form of respiratory disease in premature infants. Am J Dis Child 99:489-499

17. Ogawa Y, Fujimura M, Goto A, Kawano T, Kondo T, Nakae N 1992 Epidemiology of neonatal chronic lung disease in Japan. Acta Pediatr Jpn 34:663-667

18. Mammel MC, Green TP, Johonson DE, Thompson TR 1983 Controlled trial of dexamethasone therapy in infants with bronchopulmonary dysplasia. Lancet 1:1356-1358
19. Avery GB, Fletcher AB, Kaplan M, Brudno DS 1985 A controlled trial of dexamethasone in respirator-dependent infants with bronchopulmonary dysplasia. Pediatrics 75:106-111

20. Briggs GG 1998 Dexamethasone. In: Briggs GG, Freeman RK, Yaffe SJ (eds) Drugs in Pregnancy and Lactation, 5th Ed. Williams \& Wilkins, Baltimore, pp 306-308

21. Silverman M 1989 Long-term lung function is unaffected by antenatal dexamethasone treatment. Pediatr Pulmonol 6:210-211.

22. Smolders-de Haas H, Neuvel J, Schmand B, Treffers PE, Koppe JG, Hoeke J 1990 Physical development and medical history of children who were treated antenatally with corticosteroids to prevent respiratory distress syndrome: a 10- to 12-year follow-up. Pediatrics 86:65-70

23. Wing DA, Paul RH, Millar LK 1996 Management of the symptomatic placenta previa: a randomized, controlled trial of inpatient versus outpatient expectant management. Am J Obstet Gynecol 175:806-811

24. Jobe AH, Newnham J, Willet K, Ikegami M 1998 Fetal versus maternal and gestational age effects of repetitive antenatal glucocorticoids. Pediatrics 102:11161125

25. Banks BA, Cnaan A, Morgan MA, Parer JT, Merrill JD, Ballard PL, Ballard RA 1999 Multiple course of antenatal corticosteroids and outcome of premature neonates. Am J Obstet Gynecol 181:709-717

26. Rudolph AM, Roman C, Gournay V 1999 Perinatal myocardial DNA and protein changes in the lamb: effect of cortisol in the fetus. Pediatr Res 46:141-146

27. Garite TJ, Rumney PJ, Briggs GG, Harding JA, Nageotte MP, Towers GV, Freeman RK 1992 A randomized, placebo-controlled trial of betamethasone for the prevention of respiratory distress syndrome at 24 to 28 weeks' gestation. Am J Obstet Gynecol $166: 646-651$ 